\title{
Attrition of Medical Students in International Medical University - 2002 to 2007
}

\author{
Hematram Yadav ${ }^{1}$, Noraidah Yusoff ${ }^{2}$, Kok Leong $\operatorname{Tan}^{1}$
}

\begin{abstract}
Objectives: To estimate the attrition rate and identify common characteristics of medical students who withdrew from an undergraduate medical programme.

Methods: This study retrospectively analysed records of students who withdrew from medical programme among 10 student cohorts between 2002 and 2007 in the pre-clinical phase at the International Medical University (IMU), Malaysia. Data on student gender, pre-university entry, banding and English qualification (Malaysian University English Test [MUET] or International English Language Testing System [IELTS]) were studied and compared with all students entering the university during the same study period.
\end{abstract}

Results: Among the 10 student cohorts between 2002 and 2007, a total of 112 out of 1,890 students withdrew from medical programme with more male than female students. Attrition was more common among students with Australian University Foundation, Canadian Pre-University and Ministry of Education Malaysia pre-university entry qualifications. Students with 'high' academic banding of entry qualifications and poor English qualification grades exhibited higher rates of attrition.

Conclusion: The attrition rate among medical students in IMU between 2002 and 2007 was $5.9 \%$. IMU needs to review the minimum academic criteria for admission into the medical programme in order to reduce the attrition rate. It is suggested to select students of 'lower banding' with better English grades while reducing the intake among students from 'higher banding' and lower English grades.

Keywords: pre-university entry, banding, Malaysia

\section{Introduction}

Student attrition is an important issue for all medical universities worldwide. Medical universities are paying increased attention to reduce student attrition because it results in

${ }^{1}$ Community Medicine Division,

${ }^{2}$ Academic Affairs Department,

International Medical University, Bukit Jalil, Malaysia

Corresponding Author:

Kok Leong Tan

International Medical University

126, Jalan Jalil Perkasa 19,

Bukit Jalil,57000 Kuala Lumpur,

Malaysia

Email: kokleong_tan@imu.edu.my considerable costs to the student (e.g. fees, opportunity costs, emotional costs) and to the institution (e.g. loss of fees, recruitment costs, tuition costs). Each student lost from a medical programme represents a waste of a career opportunity, with emotional trauma and uncertainty for the student and his /her family and friends (Coles, 1994). Attrition of university students is mostly due to academic reasons (despite high admission standards), followed by financial reasons and occasionally personal reasons (Titus, 2004).

The International Medical University (IMU) began in 1992 as the International Medical College, Malaysia's first private medical college and became a university in 1999. IMU Medical programme is structured in two phases: Phase 1, Medical Sciences and Phase 2, Clinical Training. Phase 1 of 5 semesters from Semester 1 to Semester 5 ( $2 \frac{1}{2}$ years) focuses on the medical sciences and is undertaken at the university's campus 
in Bukit Jalil, Malaysia with two intakes per year February and August. To avoid student losses, the problem must be quantified and remedial action sought. However, information about the number of students lost and the characteristics among the students from medical universities are not widely available. In an attempt to address these issues, a survey was performed involving assessment of records of all students who withdrew from the medical programme in IMU, Malaysia among 10 student cohorts from 2002 to 2007. The objective of this study was to estimate the attrition rate and identify common characteristics of medical students who withdrew from the medical course.

\section{Methods}

This was a retrospective study of the student records of the students who withdrew from the medical course in their pre-clinical phase at IMU. The student medical programme records from semester 1 to 5 , among 10 student cohorts between 2002 and 2007, were included in the study. Data on student gender, pre-university entry, English qualifications (on their MUET or IELTS) were noted.

Various entry qualifications are accepted for entry into the IMU Medical programme, and the Academic Banding Table is a device used to equate one entry qualification against another. It is based on set criteria with the scoring system taking into account the type of pre-university entry, the subjects taken, and the scores or grades obtained for each subject. The grades in Band 1 constitute as being the best, whereas Band 4 represented the minimum entry qualification accepted by the IMU.

Data of students who withdrew from the programme were compared with all of the enrolled students in the university during the same study period. Data was entered and analyzed using 'Statistical Package for Social Sciences Software' (SPSS) Version 11.5. Descriptive statistics were used for all the variables studied while Pearson Chi-square test was used wherever appropriate.

\section{Results}

Among the 10 student cohorts between 2002 and 2007, 112 out of a total of 1,890 students withdrew from medical programme with an attrition rate of $5.9 \%$. Attrition among male students was higher compared to female students. Comparison of attrition in terms of pre-university entry level showed that the highest attrition was among students with the Australian University Foundation qualification
(23.1\%), followed by among the Canadian preuniversity $(17.4 \%)$ and the Ministry of Education Malaysia Matriculation (17.3\%) qualifications. The attrition rate increased as the banding increased $(1.6 \%$ among band 1 students to $13.4 \%$ among band 4 students). Students from bands 3 to 4 , students who chose the IMU clinical school (IMU CS), students with English (MUET) scores of 2 to 3 and English (IELTS) scores of less than 7.0 also had a higher attrition rate.

\section{Discussion}

Student attrition is a problem faced by universities worldwide. In this study, the attrition rate among medical students was $5.9 \%$. Studies have shown that the attrition rate among British universities was between $0.5 \%$ and $13 \%$ (Green et al., 1993) while in the United States of America (US) the rate ranges from $2 \%$ to $16 \%$ (Gupta, 1991).

Our findings showed that attrition was higher among male students. Studies have shown that male students were more likely to withdraw from a university course than female students (Fogelman et al., 1981). Gupta (1991) reported a male to female attrition rate of 1.5:1. The higher attrition among male students may be related to study habits, personal problems or coping skills.

Most universities select students to their medical course based on high academic standards, with a structured interview to assess personal characteristics (Collins et al., 1995). Our findings showed that the attrition rate increases as banding increase (i.e. as the academic standards reduce). Fogelman et al. (1981) suggested that poor academic performance, as measured through standard unit change in high school GPA, was a predictor of early attrition among medical students. Titus (2004) suggested that a one standard unit increase in high school GPA was associated with a $2 \%$ increase in student persistence.

A certain percentage of attrition among medical students in any medical university is inevitable if academic standards of medical education are to be maintained and if unsuitable students are to be prevented from graduating. As there is a surplus of applications to the IMU, the emphasis should be on recruiting the best rather than students with the potential of failing. It would be logical to reduce attrition to a minimum on both humanitarian and economic grounds. 


\section{Conclusion}

IMU needs to review the minimum academic criteria for admission into the medical course in order to reduce the attrition rate. IMU also need to pay special attention to students with pre-university entry from Australian University Foundation, Canadian Pre-University and Ministry of Education Malaysia Matriculation, as well as to students from higher bands and a poor score/ grade in English. Since the report was based on a student cohort from the medical programme, the findings cannot be extrapolated to other programmes in IMU or to similar programmes in other universities.

\section{References}

Coles, C. (1994) Learning to cope: stress and medical career development in the UK. Medical Education, 28, pp. 18-25.
Collins, J.P,. White, G.R. \& Kennedy, J.A. (1995) Entry to medical school, an audit of traditional requirements. Medical Education, 29, pp. 22-28.

Fogelman, B.Y.S., Vander Zwagg, R. (1981) Demographic, situational and scholastic factors in medical school attrition. Southern Medical Journal, 74, pp. 602-606.

Green, A., Peter, T.J. \& Webster, D.J.T. (1993) Preclinical progress in relation to personality and academic profiles. Medical Education, 27, pp. 137-142.

Gupta, G.C. (1991) Student attrition: A challenge for allied health education programmes. Journal of American Medical Association, 266, pp. 963967.

Titus, M.A. (2004) An examination of the influence of institutional context on student persistence at 4-year colleges and universities: A multilevel approach. Research in Higher Education, 45, 7, pp. 673-699. 